University of Wollongong

Research Online

Faculty of Engineering and Information

Faculty of Engineering and Information

Sciences - Papers: Part B

Sciences

2017

\title{
Load and moment interaction diagram for circular concrete columns reinforced with GFRP bars and GFRP helices
}

Hogr Karim

University of Wollongong, hmjkk643@uowmail.edu.au

M Neaz Sheikh

University of Wollongong, msheikh@uow.edu.au

Muhammad N. S Hadi

University of Wollongong, mhadi@uow.edu.au

Follow this and additional works at: https://ro.uow.edu.au/eispapers1

Part of the Engineering Commons, and the Science and Technology Studies Commons

Research Online is the open access institutional repository for the University of Wollongong. For further information contact the UOW Library: research-pubs@uow.edu.au 


\title{
Load and moment interaction diagram for circular concrete columns reinforced with GFRP bars and GFRP helices
}

\begin{abstract}
This paper presents analytical and experimental studies on the axial load-bending moment behavior of glass fiber-reinforced polymer (GFRP) bars and helices RC columns. The nominal axial load and bending moment of the columns were analyzed based on the stress-strain behavior of the cross-sectional components. A numerical integration method was used to determine the compressive force of concrete in the compression region. The analytical results were verified with experimental results of 12 circular specimens reinforced with GFRP bars and GFRP helices. Out of these 12 specimens, eight specimens were taken from available literature and four specimens were tested in this study. The influences of different parameters such as loading conditions, spacing of the GFRP helices, and wrapping the specimens with carbon fiber-reinforced polymer (CFRP) sheets on the behavior of GFRP-RC specimens were investigated. A parametric study was also carried out to investigate the effects of longitudinal and transverse GFRP reinforcement ratio and slenderness ratio on the axial load-bending moment diagrams of GFRP-RC columns. It was found that the slenderness effect is more pronounced on the confined cross sections under eccentric loads at the ultimate state condition.
\end{abstract}

\section{Keywords}

bars, gfrp, reinforced, columns, concrete, helices, circular, load, diagram, interaction, moment

\section{Disciplines}

Engineering | Science and Technology Studies

\section{Publication Details}

Karim, H., Sheikh, M. Neaz. \& Hadi, M. N. S. (2017). Load and moment interaction diagram for circular concrete columns reinforced with GFRP bars and GFRP helices. Journal of Composites for Construction, 21 (1), 04016076-1-04016076-12. 


\title{
Load and Moment Interaction Diagram for Circular Concrete Columns Reinforced with
} GFRP Bars and GFRP Helices

\author{
Hogr Karim $^{1}$ \\ ${ }^{1}$ Ph.D. Candidate, School of Civil, Mining and Environmental Engineering, University of \\ Wollongong, Australia. Email: hmjkk643@uowmail.edu.au \\ M. Neaz Sheikh ${ }^{2}$ \\ ${ }^{2}$ Senior Lecturer, School of Civil, Mining and Environmental Engineering, University of \\ Wollongong, Australia. Email: msheikh@uow.edu.au \\ Muhammad N. S. Hadi ${ }^{3}$, F. ASCE \\ ${ }^{3}$ Associate Professor, School of Civil, Mining and Environmental Engineering, University of \\ Wollongong, Australia (corresponding author). Email: $\underline{\text { mhadi@uow.edu.au }}$
}

Abstract: This paper presents analytical and experimental studies on the axial load-bending moment behavior of Glass Fiber Reinforced Polymer (GFRP) bars and helices Reinforced Concrete (RC) columns. The nominal axial load and bending moment of the columns were analysed based on the stress-strain behavior of the cross-sectional components. A numerical integration method was used to determine the compressive force of concrete in the compression region. The analytical results were verified with experimental results of 12 circular specimens reinforced with GFRP bars and GFRP helices. Out of these 12 specimens, eight specimens were taken from available literature and four specimens were tested in this study. The influences of different parameters such as loading conditions, spacing of the GFRP helices and wrapping the specimens with Carbon Fiber Reinforced Polymer (CFRP) sheets on the behavior of GFRP-RC specimens were investigated. A parametric study was also carried out to investigate the effects of longitudinal and transverse GFRP reinforcement ratio and slenderness ratio on the axial load-bending moment diagrams of GFRP-RC columns. It was 
found that the slenderness effect is more pronounced on the confined cross-sections under eccentric loads at the ultimate state condition.

Keywords: Reinforced concrete, Column, GFRP bar, CFRP wrapping, Eccentric load

\section{Introduction}

Fiber Reinforced Polymer (FRP) bar is considered as a viable alternative to steel reinforcing bar in Reinforced Concrete (RC) members particularly in harsh, corrosive, and costal environments (Bank 2006). This is because steel bars may corrode in such environments and cause deterioration of RC members. The cost of repair and rehabilitation of deteriorated structures may be significant (Sheikh and Légeron 2014). For instance, in the United States, the annual repair and replacement cost for bridge substructures (bridge piers and columns) is about two billion dollars and for marine piling is about one billion dollars (Mohamed et al. 2014). FRP bars are corrosion-resistant and possess high tensile strength to weight ratio. Steel bars, however, cannot be simply replaced with GFRP bars due to differences in the mechanical properties of the two materials (ISIS 2007). Also, FRP bars are anisotropic materials and their compressive strength are relatively smaller than their tensile strength (Chaallal and Benmokrane 1993, Benmokrane et al. 1995). A number of experimental studies were carried out to investigate the influences of replacing steel bars with FRP bars on the behavior of square and circular concrete columns under concentric loads (De Luca et al. 2010, Tobbi et al. 2012, Afifi et al. 2014, Mohamed et al. 2014, Karim et al. 2015). It was reported that the load carrying capacity of the GFRP-RC columns is about 13 to $16 \%$ smaller than the load carrying capacity of the corresponding steel-RC columns. Also, the contribution of the GFRP longitudinal bars is about $3 \%$ to $10 \%$ of the total load carrying capacity of the RC columns compared to the contribution of $12 \%$ to $16 \%$ for the same amount of longitudinal steel bars. 
Experimental studies on the behavior of FRP-RC columns under eccentric loads are limited. Amer et al. (1996) tested eight rectangular concrete columns reinforced with CFRP bars and steel ties under different eccentric loads. They observed that the calculated failure loads for the columns under eccentric loads were higher than the measured failure loads. However, the calculated and measured failure moments were in close agreement. Mirmiran et al. (2001) conducted a parametric study on the slenderness effect of FRP-RC columns and suggested to reduce the slenderness limit from 22 to 17 for GFRP-RC columns with at least $1 \%$ reinforcement ratio. Choo et al. (2006a) observed that FRP-RC cross-section sometimes faced a brittle tensile rupture of FRP bars before the axial load-bending moment diagrams reach the pure bending condition. Therefore, Choo et al. (2006b) introduced a set of equations to determine minimum FRP reinforcement ratio for rectangular cross-section under pure bending loads. Hadi et al. (2016) carried out experimental studies on GFRP-RC circular columns under different load conditions. Hadi et al. (2016) reported that GFRP-RC columns sometimes achieve two peak loads corresponding to the unconfined cross-section (concrete core and cover) and confined concrete core (concrete cover was considered to have spalled off). Also, they suggested that the axial load-bending moment diagrams can be drawn based on five points for over-reinforced FRP-RC short columns.

Over the last three decades a significant number of studies have been conducted on the effects of confining concrete columns with FRP sheets and tubes (Hadi 2007, Hadi 2010, Hadi and Widiarsa 2012, Hadi et al. 2013, Hadi et al. 2015). The studies showed that FRP confinement can enhance the strength and ductility of the columns. Therefore, in this study CFRP wrapping technique is used to confine the GFRP-RC columns in order to enhance the load 
carrying capacity and bending moment of the GFRP-RC specimens. Also, CFRP wrapping works as a barrier when the RC specimens face harsh environments.

The behavior of GFRP-RC columns (particularly circular cross-section) under eccentric loads has not been adequately investigated in the available literature. Also, there is no guideline in ACI 440.1R-15 (ACI 2015) for design of FRP-RC columns. Hence, experimental and analytical investigations are needed to assess the behavior of GFRP-RC columns. Also, the parameters that affect the performance of GFRP-RC columns need to be investigated.

\section{Analytical Consideration}

In this study, two types of concrete stress-strain models were considered: one for unconfined concrete and the other for confined concrete core with GFRP helices and CFRP sheets. Generally, the stress-strain behavior of concrete in the literature was based on concentric compression tests. The assumption of using the same stress-strain behavior for concrete in flexure is widely used for unconfined concrete. However, this assumption is questionable for the stress-strain behavior of confined concrete (Jiang and Teng 2012). In contrast, Saadatmanesh et al. 1994, Jiang and Teng 2012, Jiang and Teng 2013 reported that this assumption is applicable for circular confined concrete cross-sections. Hence, the stress-strain behavior of unconfined and confined concrete under concentric load was used to represent the stress-strain behavior of concrete in the compression side under eccentric and flexural loads in this paper.

\section{Unconfined concrete stress-strain model}

A continuous curve proposed by Popovics (1973) is adopted to model the stress-strain behavior of unconfined concrete. 


$$
\begin{gathered}
f_{c}=\frac{f_{c o}^{\prime} \mu\left(\varepsilon_{c} / \varepsilon_{c o}\right)}{\mu-1+\left(\varepsilon_{c} / \varepsilon_{c o}\right)^{\mu}} \\
\mu=\frac{E_{1}}{E_{1}-f_{c o}^{\prime} / \varepsilon_{c o}} \\
\varepsilon_{c o}=0.0005 f_{c o}^{\prime 0.4} \quad(\mathrm{MPa}) \\
E_{1}=4730 \sqrt{f_{c o}^{\prime}} \quad(\mathrm{MPa})
\end{gathered}
$$

99 where $\varepsilon_{c}$ is the axial concrete strain at any concrete stress $\left(f_{c}\right), f_{c o}^{\prime}$ is the unconfined concrete 100 strength which is equal to $85 \%$ of cylinder compressive strength $\left(f_{c}^{\prime}\right)$ at age 28-days, $\varepsilon_{c o}$ is 101 the unconfined concrete strain corresponding to $f_{c o}^{\prime}$, and $E_{1}$ is the elastic modulus of concrete 102 (ACI 2014).

\section{Confined concrete stress-strain model}

105 A confined stress-strain model proposed in Lam and Teng (2003) is adopted to model the 106 stress-strain behavior of confined concrete core.

$$
\begin{gathered}
f_{c}=E_{1} \varepsilon_{c}-\frac{\left(E_{1}-E_{2}\right)^{2}}{4 f_{c o}^{\prime}} \varepsilon_{c}{ }^{2} \text { for } \varepsilon_{c}<\varepsilon_{t} \\
f_{c}=f_{c o}^{\prime}+E_{2} \varepsilon_{c} \text { for } \varepsilon_{t} \leq \varepsilon_{c} \leq \varepsilon_{c c} \\
\varepsilon_{t}=\frac{2 f_{c o}^{\prime}}{E_{1}-E_{2}} \\
E_{2}=\frac{f_{c c}^{\prime}-f_{c o}^{\prime}}{\varepsilon_{c c}}
\end{gathered}
$$

107 where $E_{2}$ is the slope of the second ascending part of stress-strain curve of confined concrete, $108 \varepsilon_{t}$ is the strain corresponding to the transition point between the first and the second 109 ascending parts of stress-strain curve of confined concrete and $\varepsilon_{c c}$ is the compressive axial 110 strain corresponding to the ultimate confined concrete strength $\left(f_{c c}^{\prime}\right)$. The $f_{c c}^{\prime}$ and $\varepsilon_{c c}$ can be 111 calculated using Eqs. (8) and (9) as proposed in Karim et al. (2014). 


$$
\begin{gathered}
f_{c c}^{\prime}=k_{c} f_{c o}^{\prime} \\
\varepsilon_{c c}=k_{c}{ }^{2} \varepsilon_{c o} \\
k_{c}=\frac{f_{c o}^{\prime}+5 f_{l}}{f_{c o}^{\prime}+0.5 f_{l}}
\end{gathered}
$$

112 where $k_{c}$ is the confinement coefficient factor and $f_{l}$ is the lateral pressure which can be

113 calculated using Eqs. (11) and (12) for GFRP helices and CFRP sheets, respectively.

$$
\begin{gathered}
f_{l}=\frac{\pi d_{b}{ }^{2} k_{\varepsilon} f_{f b}}{2 d_{c} s} \\
f_{l}=\frac{2 t_{f} k_{\varepsilon} f_{f u}}{h}
\end{gathered}
$$

114

where $d_{b}$ is the diameter of the helices bars, $k_{\varepsilon}$ is the ratio of the hoop rupture strain to the ultimate tensile strain of the confining materials, $f_{f b}$ is the tensile strength of the bent GFRP bar or GFRP helix, $d_{c}$ is the diameter of the confined concrete core which is enclosed by the centerline of the helices, $s$ is the pitch of the GFRP helices, $t_{f}$ is the total thickness of the CFRP sheets, $f_{f u}$ is the ultimate tensile strength of the CFRP sheets and $h$ is the diameter of the specimens. The value of $k_{\varepsilon}$ is recommended to be 0.55 for the CFRP sheets in ACI 440.2R-08 (ACI 2008). However, $k_{\varepsilon}=0.55$ underestimates the actual value of the $k_{\varepsilon}$ (Bisby and Ranger 2010, Hadi et al. 2013). Therefore, the value of $k_{\varepsilon}$ was found using Eq. (13), as proposed in Ozbakkaloglu and Lim (2013).

$$
k_{\varepsilon}=0.9-2.3 f_{c o}^{\prime} \times 10^{-3}-0.75 E_{f} \times 10^{-6}
$$

where $E_{f}$ is the tensile elastic modulus of the CFRP sheets. The value of $k_{\varepsilon}$ for the GFRP helices has not been generalized due to insufficient experimental studies. Hence, the recorded strain value for the GFRP helices was used in this study as reported in the experimental results. The tensile strength of the bent GFRP bar or helix is lower than its ultimate tensile strength because GFRP bars are not isotropic. Hence, different directions of the applied load lead to the reduction of the ultimate tensile strength of the GFRP bars (Ahmed et al. 2010). 
The tensile strength of the GFRP helices can be found using Eq. (14), as recommended in ACI 440.1R-15 (ACI 2015).

$$
f_{f b}=\left(0.05 \frac{r_{b}}{d_{b}}+0.3\right) f_{f u} \leq f_{f u}
$$

where $r_{b}$ is the inner radius of the helices and $f_{f u}$ is the ultimate tensile strength of the GFRP straight bars. For the specimens in the third group (CG6-G60), the concrete cover was confined only by the CFRP sheets, so the $f_{l}$ in Eq. (8) was calculated using Eq. (12). Also, concrete core was confined by the GFRP helices and the CFRP sheets, so the $f_{l}$ in Eq. (8) was calculated using the combination of both Eqs. (11) and (12). The confined concrete strength for the gross cross-section can be found using Eq. (15), as recommended in Lee et al. 2010, Hu and Seracino 2014, Shirmohammadi et al. 2015.

$$
f_{c c}^{\prime}=\frac{f_{c c, \text { cover }}^{\prime} A_{\text {cover }}+f_{c c, \text { core }}^{\prime} A_{\text {core }}}{A_{g}}
$$

where $f_{c c \text {,cover }}^{\prime}$ and $f_{c c, \text { core }}^{\prime}$ are the confined concrete strength of the concrete cover and core, respectively, and $A_{\text {cover }}$ and $A_{\text {core }}$ are the areas of concrete cover and core, respectively, and $A_{g}$ is the gross area of the concrete cross-section.

\section{Analytical peak axial load-bending moment diagrams}

Based on the observations in Hadi et al. (2016), two analytical peak axial load-bending moment $\left(P_{n}-M_{n}\right)$ diagrams were drawn for the GFRP-RC specimens corresponding to the first and the second peak axial loads. In the first peak $P_{n}-M_{n}$ diagram, the concrete crosssection (concrete core and cover) was considered as unconfined concrete because the confinement was not considerably activated. In the second peak $P_{n}-M_{n}$ diagram, the concrete core was considered as fully confined concrete and the effect of concrete cover was ignored (concrete cover was considered to have spalled off). The analytical peak $P_{n}-M_{n}$ diagrams were drawn based on five points, as recommended in Hadi et al. (2016) and shown 
in Fig. 1. The analytical peak $P_{n}-M_{n}$ diagrams for the GFRP-RC specimens were drawn based on the same assumptions that are applicable to steel-RC columns. The assumptions are: (i) plane sections remain plane after deformation, (ii) perfect bond exits between the reinforcement and the surrounding concrete and (iii) the tensile strength of concrete can be neglected (Choo et al. 2006a). In addition, a linear elastic stress-strain relationship was adopted for the GFRP bars in tension and compression. Also, based on the experimental studies of Chaallal and Benmokrane (1993) and Deitz et al. (2003), it can be assumed that the compressive and tensile moduli of elasticity of GFRP bars are approximately equal.

In order to calculate the axial load and bending moment at each point, arbitrarily values for $Z$ were considered, where $Z$ is the ratio of maximum tensile strain of the GFRP bars in the tension side to the ultimate compressive strain in the extreme fiber in the compression side. In this study, compression strain, stress and force are considered as positive and tensile strain, stress and force are considered as negative. From Fig. 2(a, b), by similar triangles, the depth of neutral axis $(c)$ and strain in each of the GFRP bars $\left(\varepsilon_{f i}\right)$ can be calculated as:

$$
\begin{gathered}
c=\frac{d_{4}}{1-Z} \\
\varepsilon_{f i}=\left(1-\frac{d_{i}}{c}\right) \varepsilon_{c u}
\end{gathered}
$$

where $d_{i}$ is the distance between the center of the $i^{\text {th }}$ GFRP bar to the extreme compression fiber in the compression side, $\varepsilon_{c u}$ is the ultimate concrete compressive strain which is equal to 0.003 in the first peak load and equal to $\varepsilon_{c c}$ in the second peak load. Also, the forces in each of the GFRP bars $\left(F_{f i}\right)$ and the compression force in concrete $\left(F_{c}\right)$ in the compression side can be determined as:

$$
F_{f i}=E_{f} \varepsilon_{f i} A_{f i}
$$




$$
F_{c}=\int_{0}^{c} \int_{-x}^{x} f_{c} d_{x} d_{y}
$$

171 where $\varepsilon_{f i}$ and $A_{f i}$ are the strain and the cross-sectional area of the $i^{\text {th }}$ GFRP bar, respectively,

172 and $f_{c}$ is the concrete stress which is considered as unconfined concrete stress (Eq. 1) for the

173 first peak load and considered as confined concrete stress (Eq. 5) for the second peak load.

174 Numerical integration method was used to solve Eq. (19). The cross-section of the specimen

175 was divided into $n$ number of strips which are small enough to obtain accurate results as

176 shown in Fig. 1. The average width and strain of each strip can be calculated as:

$$
\begin{gathered}
b_{i}=2 \sqrt{r_{c}^{2}-\left[r_{c}-\left(i-\frac{1}{2}\right) t\right]^{2}} \\
\varepsilon_{c i}=\left[1-\left(i-\frac{1}{2}\right) \frac{t}{c}\right] \varepsilon_{c u}
\end{gathered}
$$

177 where $b_{i}$ is the average width of the $i^{\text {th }}$ concrete strip, $r_{c}$ is the radius of the concrete cross178 section which is equal to $h / 2$ for the first peak load and equal to $d_{c} / 2$ for the second peak 179 load, $\varepsilon_{c i}$ is the average strain for the $i^{t h}$ concrete strip, and $t$ is the depth of the strips which is 180 taken as $1 \mathrm{~mm}$ in this study. For the specimens confined with CFRP sheets the value of $r_{c}$ is 181 equal to $h / 2$ for the second peak load because concrete cover did not spall off. By 182 substituting the values of $\varepsilon_{c i}$ in Eqs. (1) and (5), the unconfined and confined concrete 183 stresses can be calculated in each concrete strip in the compression side. Eventually, the 184 compression force of each concrete strip $\left(F_{c i}\right)$ in the compression side can be determined as:

$$
F_{c i}=f_{c i} b_{i} t
$$

185 The nominal axial load $\left(P_{n}\right)$ and the bending moment $\left(M_{n}\right)$ of the GFRP-RC specimens can 186 be calculated by summation of the forces in the concrete cross-section and taking moment of 187 the forces around the centroid of the concrete cross-section:

$$
P_{n}=\sum_{i=1}^{n} F_{c i}+\sum_{i=1}^{m} F_{f i}
$$




$$
M_{n}=\sum_{i=1}^{n} F_{c i}\left[r_{c}-\left(i-\frac{1}{2}\right) t\right]+\sum_{i=1}^{m} F_{f i}\left(r_{c}-d_{i}\right)
$$

where $m$ is the total number of the longitudinal bars in the RC cross-section. An MS-Excel spread-sheet was prepared to implement the calculation procedures presented in this paper for the load and moment interaction diagram of circular concrete columns reinforced with GFRP bars and GFRP helices.

\section{Experimental Program}

The experimental part of this study consisted of testing three groups of GFRP-RC specimens. The full descriptions of specimens in the first (G6-G60) and the second (G6-G30) groups can be found in Hadi et al. (2016). All the specimens were $205 \mathrm{~mm}$ in diameter and $800 \mathrm{~mm}$ in height. The reinforcements of specimens in the third group (CG6-G60) were the same as the specimens in Group G6-G60 (Table 1). However, specimens of the third group (CG6-G60) were externally confined with two layers of CFRP sheets with a total thickness $\left(t_{f}\right)$ of 0.9 $\mathrm{mm}$ in the hoop direction. The letter "C" at the beginning of the third group name indicates that the specimens were confined with CFRP sheets. All the specimens were cast in the same day with one batch of ready mix concrete. The average concrete strength (37 MPa) was found by testing three cylinders $(100 \mathrm{~mm} \times 200 \mathrm{~mm})$ at 28-days. Each group consisted of four specimens. Specimens of each group were tested under four different loading conditions which were concentric, $25 \mathrm{~mm}$ eccentric, $50 \mathrm{~mm}$ eccentric and flexural loadings. Details of the specimens are shown in Table 1.

The mechanical properties of the GFRP bars were determined according to ASTM D7205-11 (ASTM 2011). The average cross-sectional areas of \#3 and \#4 GFRP bars were measured as $95 \mathrm{~mm}^{2}$ and $168 \mathrm{~mm}^{2}$, respectively, from immersion test of the GFRP bars. Also, the ultimate tensile strength and elastic modulus were $1700 \mathrm{MPa}$ and $76 \mathrm{GPa}$, respectively, for \#3 GFRP 
bar and $1600 \mathrm{MPa}$ and $66 \mathrm{GPa}$, respectively for \#4 GFRP bar. In this study, nominal areas of the GFRP bars were considered for calculating the ultimate tensile strength and elastic modulus. This is because the sand-coat only increases bond between the bars and the surrounding concrete. The nominal diameters of \#3 and \#4 GFRP bars were $9.5 \mathrm{~mm}$ and 12.7 mm, respectively. The CFRP sheet used in this study was $75 \mathrm{~mm}$ wide with a unidirectional fibre density of $340 \mathrm{~g} / \mathrm{m}^{2}$ and thickness of $0.45 \mathrm{~mm}$. The mechanical properties of the CFRP sheets were found by coupon test as recommended in ASTM D7565-10 (ASTM 2010). Five samples of two layers of CFRP sheets with $0.9 \mathrm{~mm}$ thick, $25 \mathrm{~mm}$ width and $250 \mathrm{~mm}$ length were tested. The average maximum tensile load and the corresponding strain were 1125 $\mathrm{N} / \mathrm{mm}$ and $0.0147 \mathrm{~mm} / \mathrm{mm}$, respectively. The specimens in Group CG6-G60 were confined by wrapping two layers of CFRP sheets in the hoop direction by using wet layup technique. A mixture of epoxy resin and hardener at a ratio of 5:1 was used as a bonding agent. An overlap of $100 \mathrm{~mm}$ was applied in the hoop direction to maintain sufficient bonding strength. Afterwards, the wrapped specimens were placed in room temperature for at least 14-days to harden and cure the epoxy.

The experimental results were recorded through LVDTs attached to the loading plates and the strain gages attached to the longitudinal and helical GFRP reinforcements. For the specimens with CFRP sheets, two electrical strain gages were attached at the mid-height in the two opposite sides of the CFRP wrap to measure the strain in the hoop direction. In addition, a lazer triangulation was used to record the mid-height lateral deformation and mid-span deflection for the specimens under eccentric and flexural loads, respectively. All specimens were tested at the laboratories of the School of Civil, Mining and Environmental Engineering at the University of Wollongong. A $5000 \mathrm{kN}$ Denison compression machine was used to test the specimens. Typical test setups for the specimens are shown in Fig. 3. 


\section{Experimental Results and Discussion}

Figures 4 and 5(a, b) show the experimental axial load-deformation behavior of tested column specimens under concentric and eccentric loads, respectively. As reported in Hadi et al. (2016), there were two peak loads in the load-deformation behavior of unwrapped column specimens. The first peak load represents the maximum load carried by the concrete crosssection without considering the confinement effects. After the first peak load, cover spalling led to the reduction of the load carrying capacity of the unwrapped GFRP-RC column specimens. However, the load carrying capacity increased because of the confinements from the GFRP helices. Therefore, second peak load was observed for unwrapped specimens. First peak load was not observed for the wrapped specimens with CFRP because cover did not spall off. Consequently, it can be concluded that first peak load represents the ultimate load carrying capacity of unconfined concrete cross-section and second peak load represents the ultimate load carrying capacity of confined concrete cross-section (Karim et al. 2016).

The experimental results are reported in Tables 2-4 for specimens under concentric, eccentric and flexural loads, respectively. The experimental confined concrete strength $\left(f_{c c}^{\prime}\right)$ for the column specimens under concentric loads was calculated as:

$$
f_{c c}^{\prime}=\frac{P_{2}-P_{b a r}}{A_{c o r e}}
$$

where $P_{2}$ and $P_{b a r}$ are the second peak load and the corresponding loads carried by the longitudinal GFRP bars, respectively, and $A_{\text {core }}$ is the area of confined concrete core that is enclosed by the centerline of the GFRP helices. The ratio of hoop rupture strains to the ultimate tensile strains $\left(k_{\varepsilon}\right)$ recorded from the strain gages were about 0.333 and 0.75 for the GFRP helices and the CFRP sheets, respectively. This difference is due to the fact that the concrete core in the case of the GFRP helices was not fully confined. Therefore, a lesser ratio 
of the GFRP ultimate strain was utilised by the dilation of the concrete core. In addition, the ultimate tensile strain of the GFRP helices was about two times of the CFRP sheet.

Based on the axial load-deformation behavior of the GFRP-RC specimens, two sets of the peak $P_{n}-M_{n}$ diagrams were drawn for the GFRP-RC specimens corresponding to the first and the second peak loads. The experimental peak $P_{n}-M_{n}$ diagrams were drawn based on four points which were concentric, $25 \mathrm{~mm}$ eccentric, $50 \mathrm{~mm}$ eccentric and flexural loadings. The experimental bending moments at the mid-height of the column specimens under eccentric loads were calculated as:

$$
\begin{aligned}
& M_{1}=P_{1}\left(e_{i}+\delta_{1}\right) \\
& M_{2}=P_{2}\left(e_{i}+\delta_{2}\right)
\end{aligned}
$$

where $M_{1}$ and $\delta_{1}$ are the bending moment and lateral deformation, respectively, corresponding to the first peak load $\left(P_{1}\right), M_{2}$ and $\delta_{2}$ are the bending moment and lateral deformation, respectively, corresponding to the second peak load $\left(P_{2}\right)$, and $e_{i}$ is the applied initial load eccentricity at the ends of the column specimens. The experimental bending moments at mid-span of the beam specimens were calculated as:

$$
\begin{aligned}
& M_{1}=\frac{1}{2} P_{1} a \\
& M_{2}=\frac{1}{2} P_{2} a
\end{aligned}
$$

where $a$ is the shear span length, or the distance between the support and the closer loading point ( $a=233.3 \mathrm{~mm}$ in this study).

Figure 6(a) shows the experimental peak $P_{n}-M_{n}$ diagrams for the tested specimens in terms of the first peak loads. It can be observed that reduction in the spacing of the GFRP helices did not considerably change the peak $P_{n}-M_{n}$ diagram of the GFRP-RC specimens because the passive confinement due to the GFRP helices was not considerably activated in the first 
peak load. However, it can be observed from Fig. 6(b) that the GFRP bars and helices improved the experimental second peak $P_{n}-M_{n}$ diagram of the GFRP-RC specimens. This is because the modulus of elasticity of the GFRP bars is small. Hence, larger deformation and lateral expansion are needed to achieve higher stresses in the GFRP bars and helices. The efficiency of confining the specimens with the CFRP sheets on improving the strength capacity of the specimens increased with decreasing the eccentricity of the applied axial load. This is because the area of confined concrete in the compression region increases with the reduction in the eccentricity.

Figure 7(a, b) shows the experimental and analytical peak $P_{n}-M_{n}$ diagrams corresponding to the first and the second peak loads, respectively, for the tested specimens. The calculated results show good agreements with the experimental results especially for the column specimens. However, the experimental bending moment of the GFRP-RC beam specimens was greater than the calculated results. This may be because the shear span of the beam specimens was smaller than two times of the effective depth of the concrete cross-section. It can be observed that all experimental results are greater than the analytical results. Except the beam specimens, the differences between the experimental and analytical results were about $10 \%$.

\section{Parametric Study}

In order to investigate the effects of different parameters such as longitudinal GFRP reinforcement ratio, confinement ratio and slenderness ratio on the first and the second peak $P_{n}-M_{n}$ diagrams of GFRP-RC columns, a parametric study was conducted. Specimens in the first group (G6-G60) were employed as reference for the parametric study. The peak $P_{n}-M_{n}$ diagrams that presented in this section are normalized as: 


$$
\begin{gathered}
P^{*}=\frac{P_{n}}{f_{c o}^{\prime} A_{g}} \\
M^{*}=\frac{M_{n}}{f_{c o}^{\prime} A_{g} h}
\end{gathered}
$$

where $P^{*}$ and $M^{*}$ are the normalized axial loads and bending moments, respectively. In addition, any comparison between unconfined and confined cross-sections has been made in this section are based on the ultimate state condition. The first peak $P^{*}-M^{*}$ diagram represents the ultimate condition for unconfined concrete cross-sections and the second peak $P^{*}-M^{*}$ diagram represents the ultimate condition for confined concrete cross-sections.

\section{Longitudinal reinforcement ratio}

The effect of longitudinal reinforcement ratio $\left(\rho_{f}\right)$ on the first and the second peak $P^{*}-M^{*}$ diagrams was investigated using the analytical models presented in Section "Analytical peak axial load-bending moment diagrams”. The $\rho_{f}$ ranged between $1 \%$ to $4 \%$ after AS $3600-2009$ (AS 2009). Figure 8(a, b) shows the effects of changing $\rho_{f}$ on the peak $P^{*}-M^{*}$ diagrams. Increasing $\rho_{f}$ led to increasing the strength capacity of the specimens in the first and the second peak $P^{*}-M^{*}$ diagrams. The strength improvements due to increasing $\rho_{f}$ were more pronounced in the second peak $P^{*}-M^{*}$ diagram. This is because the strain distribution (compression and tension) in the cross-sections in the second peak load (confined crosssection) was much greater than that in the first peak load (unconfined cross-section). It was observed that reducing $\rho_{f}$ resulted in a great tensile strain in the tension side of the GFRP-RC cross-sections with increasing load-eccentricity, particularly in the flexural loading condition.

It can be noticed that insufficient $\rho_{f}$ sometimes leads to a brittle tensile failure of the FRP bars before the peak $P^{*}-M^{*}$ diagrams reach to the pure bending condition. This phenomenon was also observed in Choo et al. (2006a). Choo et al. (2006b) proposed a set of 
equations to limit the minimum $\rho_{f}$ for rectangular cross-section columns to prevent brittle tensile failure of FRP bars in the tension side under pure bending loads.

\section{Confinement ratio}

It is clear that confinement ratio $\left(f_{l} / f_{c o}^{\prime}\right)$ does not affect the first peak $P^{*}-M^{*}$ diagram, as the concrete cross-section considered unconfined concrete. Figure 9 shows the effects of four different $f_{l} / f_{c o}^{\prime}(0.1-0.4)$ on the second peak $P^{*}-M^{*}$ diagram. The improvements in the second peak $P^{*}-M^{*}$ diagram of the GFRP-RC columns due to increasing $f_{l} / f_{c o}^{\prime}$ were because of two reasons: (i) increasing the concrete compressive strength; and (ii) considerable increase in the concrete strain. Increasing concrete strain increases compression force in the concrete as well as the tensile forces in the FRP bars.

It is evident that providing confinement for concrete can enhance the strength and strain of the concrete. However, insufficient confinement may not be able to effectively confine the concrete core due to the weakness of the confining material to the non-uniform deformation of concrete (Mirmiran et al. 1998, Lam and Teng 2003). Mirmiran et al. (1998) introduced the Modified Confinement Ratio (MCR) to limit minimum $f_{l} / f_{c o}^{\prime}$ for externally bonded FRP. Based on MCR, no enhancement can be expected if $f_{l} / f_{c o}^{\prime}<0.15$ for circular cross-sections. Also, Lam and Teng (2003) limit the $f_{l} / f_{c o}^{\prime} \geq 0.07$ for effective confinement by the FRP jackets. Internal confinement by FRP helices or ties, however, needs greater $f_{l} / f_{c o}^{\prime}$ to be strong enough for the non-uniform deformation of concrete as well as to substitute the loss of strength due to concrete cover spalling. Providing insufficient $f_{l} / f_{c o}^{\prime}$ may not allow the specimens to obtain a second peak $P^{*}-M^{*}$ diagram comparable to the first peak one. 
Figure 10 shows the comparison between the first and the second peak $P^{*}-M^{*}$ diagrams for reference GFRP-RC specimens with three different $f_{l} / f_{c o}^{\prime}$. It can be observed that $f_{l} / f_{c o}^{\prime}=$ 0.1 cannot provide enough confinement for concrete core to reach the second peak to the first peak $P^{*}-M^{*}$ diagram. With the $f_{l} / f_{c o}^{\prime}=0.15$, the second peak $P^{*}-M^{*}$ diagram improved and partially exceeded the first peak $P^{*}-M^{*}$ diagram. However, $f_{l} / f_{c o}^{\prime}=0.2$ provides a greater second peak $P^{*}-M^{*}$ diagram for different load eccentricities than the first peak $P^{*}-M^{*}$ diagram.

\section{Slenderness ratio}

The slenderness ratio $(k L / r)$ of a RC column is defined as the ratio of effective length $(k L)$ to radius of gyration $(r)$. Figure 11 shows the effect of $k L / r$ on the peak $P^{*}-M^{*}$ diagram for a typical FRP-RC specimen, where $P_{n} e_{i}$ is the first order bending moment due to initial eccentricity $\left(e_{i}\right)$ at the ends of the specimen and $P_{n} \delta$ is the second order bending moment due to maximum lateral deformation $(\delta)$ along the height of the column. With increasing $k L / r, \delta$ becomes larger and causes a considerable decrease in the peak $P^{*}-M^{*}$ diagram. A maximum limit for $k L / r$ is, therefore, introduced in ACI 318-14 (ACI 2014) and AS 36002009 (AS 2009) based on 5\% strength reduction.

Considering to the specimens in Group G6-G60, which are pin-ended columns and bend in a single curvature, the $\delta$ is at the mid-height of the columns. The deformed shape can be assumed to be a half-sine wave as explained in Bazant et al. 1991, Jiang and Teng 2013 and shown in Fig. 12. Hence, the $\delta$ can be calculated as:

$$
\begin{gathered}
\delta=(L / \pi)^{2} \kappa_{\text {mid }} \\
\kappa_{\text {mid }}=\varepsilon_{c u} / c
\end{gathered}
$$


where $L$ is the height of the columns and $\kappa_{\text {mid }}$ is the curvature at mid-height of the columns. Figure 13(a, b) shows the effect of $k L / r$ on the first and the second peak $P^{*}-M^{*}$ diagrams of the specimens in Group G6-G60. It is evident that the effect of $k L / r$ was more pronounced in the second peak $P^{*}-M^{*}$ diagram because of greater secondary bending moments corresponding to the second peak loads.

The parameters affecting $k L / r$ for the specimens in Group G6-G60 can be investigated by assuming $M_{\text {long }} \leq 0.95 M_{\text {short }}$ at the load eccentricity ratio $\left(e_{i} / r_{c}\right)$ of 0.4 after Mirmiran et al. (2001), where $r_{c}$ is equal to $h / 2$ for the first peak $P^{*}-M^{*}$ diagram and equal to $d_{c} / 2$ for the second peak $P^{*}-M^{*}$ diagram. From Fig. 11,

$$
M_{\text {long }}=M_{\text {short }}-P_{n} \delta
$$

Solving Eq. (34) and considering $M_{\text {long }}=0.95 M_{\text {short }}, M_{\text {short }} / P_{n}=e_{i}$ and $e_{i}=0.4 r_{c}$,

$$
\delta=0.02 r_{c}
$$

By substituting Eqs. (32) and (33) in Eq. (35) and considering $k L / r=8 L / r_{c}$ for circular columns bend in a single curvature, the maximum limit for $k L / r$ can be expressed as:

$$
\frac{k L}{r}=\frac{\pi}{5} \sqrt{\frac{2(1+\gamma)}{\varepsilon_{c u}-\varepsilon_{f 4}}}
$$

where $\gamma$ is the ratio of distance between FRP bars in the tension side to FRP bars in the compression side to $2 r_{c}$ as shown in Fig. 12, and $\varepsilon_{c u}$ and $\varepsilon_{f 4}$ are the ultimate concrete compressive strain in the extreme compression fiber and maximum tensile strain in the first layer of the GFRP bars in the tension side, respectively, (Fig. 1). The maximum limit of $k L / r$ calculated using Eq. (36) for the reference GFRP-RC specimens was 18.7 which is smaller than 22 for steel-RC columns. This is because steel has a greater elastic modulus which results in a smaller absolute value for $\varepsilon_{f 4}$ in Eq. (36) and results in a greater $k L / r$. The maximum limit of $k L / r$ for the reference GFRP-RC columns was greater than the 17.2 
reported in Mirmiran et al. (2001) for GFRP-RC columns. This is because the reinforcement ratio $\left(\rho_{f}\right)$ and elastic modulus $\left(E_{f}\right)$ of the GFRP bars in this study were greater than the column specimen in Mirmiran et al. (2001). The greater $\rho_{f}$ and $E_{f}$ lead to a reduction in the absolute value of $\varepsilon_{f 4}$ in Eq. (36) and result in a greater $k L / r$. Eq. (36) can also explain the reason for a greater effect of $k L / r$ in the second peak $P^{*}-M^{*}$ diagram. This is because in confined concrete cross-section, $\varepsilon_{c u}$ and absolute value of $\varepsilon_{f 4}$ increase relatively with increasing $f_{l} / f_{c o}^{\prime}$ and result in reducing the maximum limit of $k L / r$. Consequently, it can be observed that the maximum limit of $k L / r$ reduces from 18.7 (corresponding to the first peak load) to 13.6 (corresponding to the second peak load) for the reference GFRP-RC specimens. In addition, more details on the moment magnification factor accounting for the second-order bending moment for FRP-RC slender columns can be found in Mirmiran et al. (2001).

It is evident from Fig. 13 that with small $k L / r(k L / r=16$ and 32) the strength of the columns under concentric load did not reduce considerably at the second peak $P^{*}-M^{*}$ diagram. Therefore, Fig. 14 was drawn based on 5\% strength reduction under concentric loads to show the effects of $k L / r$ on the first and the second peak $P^{*}-M^{*}$ diagrams. The maximum limit of $k L / r$ for the 5\% strength reductions under concentric loads were 18.2 and 33.4 corresponding to the first and the second peak $P^{*}-M^{*}$ diagrams. It can be observed that with an initial eccentricity, the strength of the columns at the second peak $P^{*}-M^{*}$ diagram considerably decreases. Also, the strength reductions under load eccentricity ratio $\left(e_{i} / r_{c}\right)$ of 0.4 were about $4.7 \%$ and $26.7 \%$ corresponding to the first and the second peak $P^{*}-M^{*}$ diagrams, respectively. Finally, it can be concluded that at the ultimate limit state and under eccentric loads, the effects of $k L / r$ are more pronounced on the strength reductions of confined cross-sections than unconfined cross-sections because of greater lateral deformation and secondary bending moments. 


\section{Conclusions}

422 Based on the analytical and experimental investigations carried out in this study, the 423 following conclusions can be drawn:

424 1. GFRP-RC specimens can achieve two peak axial loads. The first peak axial load represents 425 the maximum load carrying capacity of the whole cross-section without confinement effects. The second peak axial load represents the maximum load carrying capacity of the

2. Reducing the spacing of the GFRP helices or confining the specimens with CFRP sheets improved the performance of the specimens in terms of the second peak axial load-bending moment diagrams. However, the smaller pitch of the helices did not considerably change the first peak axial load-bending moment diagrams.

3. The presented calculation procedure predicted the axial load-bending moment of the specimens reasonably close to the experimental results. However, the experimental bending moment of the GFRP-RC beam specimens was greater than the calculated results. This may be because the shear span of the beam specimens was smaller than two times of the effective depth of the concrete cross-section.

4. The ratio of the hoop rupture strain to the ultimate tensile strain of the GFRP helices was considered as 0.333 in this study. However, more experimental studies are needed to ascertain a representative value of the ratio of the hoop rupture strain to the ultimate tensile strain of GFRP helices.

5. The parametric study showed that insufficient longitudinal reinforcement ratio sometimes leads to a brittle tensile failure of the FRP bars before the peak axial load-bending moment diagrams reach to the pure flexural strength. Therefore, minimum longitudinal reinforcement ratio should be provided to prevent brittle tensile failure of the FRP bars. 
6. Internal confinement by FRP helices or ties should be strong enough for the non-uniform deformation of concrete as well as to substitute the loss of strength due to the spalling of concrete cover. A confinement ratio of 0.2 can ensure improvements in the second peak axial-load bending moment diagram.

7. The effect of slenderness ratio is more obvious on the confined concrete cross-section because of large lateral deformation and second order bending moment. Also, the slenderness limit should be reduced for FRP-RC specimens because of lower modulus of elasticity of FRP bars.

The experimental and analytical investigations presented in this study indicated that GFRP bars can be used as longitudinal reinforcements to improve the performance of RC specimens in terms of axial load carrying capacity and bending moment. Also, the GFRP helices considerably confined the concrete core to sustain loads, especially after the first peak load.

\section{Acknowledgments}

The authors thank the University of Wollongong and technical officers at the High Bay laboratory, especially Mr. Fernando Escribano and Mr. Ritchie Mclean for their help in the experimental program of this study. Also, the first author thanks Kurdistan Regional Government of Iraq and University of Wollongong for supporting his Ph.D. scholarship. 


\section{References}

ACI (American Concrete Institute). (2008). "Guide for the design and construction of externally bonded FRP systems for strengthening concrete structures." ACI 440.2R-08, Farmington Hills, MI.

ACI (American Concrete Institute). (2014). "Building code requirements for structural concrete." ACI 318-14, Farmington Hills, MI.

ACI (American Concrete Institute). (2015). "Guide for the design and construction of concrete reinforced with FRP bars." ACI 440.1R-15, Farmington Hills, MI.

Afifi, M. Z., Mohamed, H. M., and Benmokrane, B. (2014). "Axial capacity of circular concrete columns reinforced with GFRP bars and spirals." J. Compos. Constr., 10.1061/(ASCE)CC.1943-5614.0000438, 04013017.

Ahmed, E. A., El-Sayed, A. K., El-Salakawy, E., and Benmokrane, B. (2010). "Bend strength of FRP stirrups: Comparison and evaluation of testing methods." J. Compos. Constr., 10.1061/(ASCE)CC.1943-5614.0000050, 3-10.

Amer, A., Arockiasamy, M., and Shahawy, M. (1996). "Ultimate strength of eccentrically loaded concrete columns reinforced with CFRP bars." Proc. of 2nd Int. Conf. on Advanced Composite Materials in Bridge and Structures (ACMBS-II), Canadian Society for Civil Engineering, Montreal, Canada.

AS (Australian Standard). (2009). "Concrete structures." AS 3600-2009, Sydney, NSW.

ASTM (American Society for Testing and Materials). (2010). "Standard test method for determining tensile properties of fiber reinforced polymer matrix composites used for strengthening of civil structures." ASTM D7565/D7565M-10, West Conshohocken, PA.

ASTM (American Society for Testing and Materials). (2011). "Standard test method for tensile properties of fiber reinforced polymer matrix composite bars." D7205/D7205M-11, West Conshohocken, PA. 
Bank, L. C. (2006). Composites for construction: Structural design with FRP materials, John Wiley \& Sons, Hoboken, New Jersey.

Bazant, Z. P., Cedolin, L., and Tabbara, M. R. (1991). "New method of analysis for slender columns." ACI Struct. J., 88(4), 391-401.

Benmokrane, B., Chaallal, O., and Masmoudi, R. (1995). "Glass fibre reinforced plastic (GFRP) rebars for concrete structures." Constr. Build. Mater., 9(6), 353-364.

Bisby, L., and Ranger, M. (2010). "Axial-flexural interaction in circular FRP-confined reinforced concrete columns." Constr. Build. Mater., 24(9), 1672-1681.

Chaallal, O., and Benmokrane, B. (1993). "Physical and mechanical performance of an innovative glass-fiber-reinforced plastic rod for concrete and grouted anchorages." Can. J. Civ. Eng., 20(2), 254-268.

Choo, C. C., Harik, I. E., and Gesund, H. (2006a). "Strength of rectangular concrete columns reinforced with fiber-reinforced polymer bars." ACI Struct. J., 103(3), 452-459.

Choo, C. C., Harik, I. E., and Gesund, H. (2006b). "Minimum reinforcement ratio for fiberreinforced polymer reinforced concrete rectangular columns." ACI Struct. J., 103(3), 460-466.

De Luca, A., Matta, F., and Nanni, A. (2010). "Behavior of full-scale glass fiber-reinforced polymer reinforced concrete columns under axial load." ACI Struct. J., 107(5), 589-596.

Deitz, D., Harik, I., and Gesund, H. (2003). "Physical properties of glass fiber reinforced polymer rebars in compression." J. Compos. Constr., 10.1061/(ASCE)10900268(2003)7:4(363), 363-366.

Hadi, M. N. S. (2007). "Behaviour of FRP strengthened concrete columns under eccentric compression loading." Compos. Struct., 77(1), 92-96.

Hadi, M. N. S. (2010). "Behaviour of reinforced concrete columns wrapped with fibre reinforced polymer under eccentric loads." Aust. J. Struct. Eng., 10(2), 169-178. 
Hadi, M. N. S., Karim, H., and Sheikh, M. N. (2016). "Experimental investigations on circular concrete columns reinforced with GFRP bars and helices under different loading conditions." J. Compos. Constr., 10.1061/(ASCE)CC.1943-5614.0000670 , 04016009.

Hadi, M. N. S., Pham, T. M., and Lei, X. (2013). "New method of strengthening reinforced concrete square columns by circularizing and wrapping with fiber-reinforced polymer or steel straps." J. Compos. Constr., 10.1061/(ASCE)CC.1943-5614.0000335, 229-238.

Hadi, M. N. S., Wang, W., and Sheikh, M. N. (2015). "Axial compressive behaviour of GFRP tube reinforced concrete columns." Constr. Build. Mater., 81, 198-207.

Hadi, M. N. S., and Widiarsa, I. B. R. (2012). "Axial and flexural performance of square RC columns wrapped with CFRP under eccentric loading." J. Compos. Constr., 10.1061/(ASCE)CC.1943-5614.0000301, 640-649.

Hu, H., and Seracino, R. (2014). "Analytical model for FRP-and-steel-confined circular concrete columns in compression." J. Compos. Constr., 10.1061/(ASCE)CC.19435614.0000394, A4013012.

ISIS (Canada Research Network). (2007). "Reinforcing concrete structures with fibre reinforced polymers." 〈http://www.isiscanada.com〉 (May 15, 2015).

Jiang, T., and Teng, J. G. (2012). "Theoretical model for slender FRP-confined circular RC columns." Constr. Build. Mater., 32, 66-76.

Jiang, T., and Teng, J. G. (2013). "Behavior and design of slender FRP-confined circular RC columns." J. Compos. Constr., 10.1061/(ASCE)CC.1943-5614.0000333, 443-453.

Karim, H., Noel-Gough, B., Sheikh, M. N., and Hadi, M. N. S. (2015). "Strength and ductility of circular concrete columns reinforced with GFRP bars and helices." Proc. 12th Int. Symp. on fiber reinforced polymers for reinforced concrete structures (FRPRCS-12) and 5th Asia-Pacific conference on fiber reinforced polymers in structures (APFIS2015), Nanjing, China. 
Karim, H., Sheikh, M. N., and Hadi, M. N. S. (2014). "Confinement of circular concrete columns: A review." Proc. of 1st Int. Engineering Conference (IEC2014) on developments in civil and computer engineering applications, Ishik University, Erbil, Iraq.

Karim, H., Sheikh, M. N., and Hadi, M. N. S. (2016). "Axial load-axial deformation behaviour of circular concrete columns reinforced with GFRP bars and helices." Constr. Build. Mater., 112, 1147-1157.

Lam, L., and Teng, J. G. (2003). "Design-oriented stress-strain model for FRP-confined concrete." Constr. Build. Mater., 17(6-7), 471-489.

Lee, J. Y., Yi, C. K., Jeong, H. S., Kim, S. W., and Kim, J. K. (2010). "Compressive response of concrete confined with steel spirals and FRP composites." J. Compos. Mater., 44(4), 481-504.

Mirmiran, A., Shahawy, M., Samaan, M., El Echary, H., Mastrapa, J. C., and Pico, O. (1998). "Effect of column parameters on FRP-confined concrete." J. Compos. Constr., 10.1061/(ASCE)1090-0268(1998)2:4(175), 175-185.

Mirmiran, A., Yuan, W., and Chen, X. (2001). "Design for slenderness in concrete columns internally reinforced with fiber-reinforced polymer bars." ACI Struct. J., 98(1), 116-125.

Mohamed, H. M., Afifi, M. Z., and Benmokrane, B. (2014). "Performance evaluation of concrete columns reinforced longitudinally with FRP bars and confined with FRP hoops and spirals under axial load." J. Bridge Eng., 10.1061/(ASCE)BE.1943-5592.0000590, 04014020.

Ozbakkaloglu, T., and Lim, J. C. (2013). "Axial compressive behavior of FRP-confined concrete: Experimental test database and a new design-oriented model." Composites Part B, 55, 607-634. 
Popovics, S. (1973). "A numerical approach to the complete stress-strain curve of concrete." Cem. Concr. Res., 3(5), 583-599.

Saadatmanesh, H., Ehsani, M. R., and Li, M. W. (1994). "Strength and ductility of concrete columns externally reinforced with fiber composite straps." ACI Struct. J., 91(4), 434447.

Sheikh, M. N., and Légeron, F. (2014). "Performance based seismic assessment of bridges designed according to Canadian Highway Bridge Design Code." Can. J. Civ. Eng., 41(9), 777-787.

Shirmohammadi, F., Esmaeily, A., and Kiaeipour, Z. (2015). "Stress-strain model for circular concrete columns confined by FRP and conventional lateral steel." Eng. Struct., 84, 395-405.

Tobbi, H., Farghaly, A. S., and Benmokrane, B. (2012). "Concrete columns reinforced longitudinally and transversally with glass fiber-reinforced polymer bars." ACI Struct. J., 109(4), 551-558. 
$594 \quad$ List of Tables

595 Table 1. Test Matrix

596 Table 2. Experimental results of tested column specimens under concentric load

597 Table 3. Experimental results of tested column specimens under eccentric loads

598 Table 4. Experimental results of tested beam specimens under flexural load

599

600

601

602

603

604

605

606

607

608

609

610

611

612

613

614

615

616

617

618 


\section{List of Figures}

620

621

622

623

624

625

626

627

628

629

630

631

632

633

634

635

636

637

638

639

640

641

Fig. 1. Schematic drawing of analytical peak $P_{n}-M_{n}$ diagram based on five points

Fig. 2. Analysis of GFRP-RC cross-section: (a) first peak load; and (b) second peak load

Fig. 3. Typical test setup; (a) CG6-G60-E25; and (b) CG6-G60-F

Fig. 4. Axial load-axial deformation behavior of column specimens tested under concentric load

Fig. 5. Axial load-deformation behavior of column specimens tested under eccentric loads: (a) 25 mm eccentricity; and (b) 50 mm eccentricity

Fig. 6. Experimental peak $P_{n}-M_{n}$ diagrams of the tested specimens: (a) first peak load; and (b) second peak load

Fig. 7. Experimental and calculated peak $P_{n}-M_{n}$ diagrams: (a) based on the first peak load of the axial load-axial deformation behavior; and (b) based on the second peak load of the axial load-axial deformation behavior

Fig. 8. Effect of $\rho_{f}$ on peak $P^{*}-M^{*}$ diagrams: (a) first peak $P^{*}-M^{*}$ diagram; and (b) second peak $P^{*}-M^{*}$ diagram

Fig. 9. Effect of $f_{l} / f_{c o}^{\prime}$ on second peak $P^{*}-M^{*}$ diagram

Fig. 10. Comparison between first and second peak $P^{*}-M^{*}$ diagrams for different $f_{l} / f_{c o}^{\prime}$

Fig. 11. Typical peak $P^{*}-M^{*}$ diagram for short and long FRP-RC columns

Fig. 12. Typical deformation of pin-ended single curvature column

Fig. 13. Effect of $k L / r$ on peak $P^{*}-M^{*}$ diagrams: (a) first peak $P^{*}-M^{*}$ diagram; and (b) second peak $P^{*}-M^{*}$ diagram

Fig. 14. First and second peak $P^{*}-M^{*}$ diagrams for short and long columns with 5\% strength reduction under concentric load 
Table 1. Test Matrix

\begin{tabular}{|c|c|c|c|c|c|}
\hline Group & Specimen ${ }^{a}$ & $\begin{array}{l}\text { Longitudinal } \\
\text { reinforcement }\end{array}$ & $\begin{array}{l}\text { Transverse } \\
\text { reinforcement }\end{array}$ & $\begin{array}{c}\text { External } \\
\text { confinement }\end{array}$ & $\begin{array}{c}\text { Test } \\
\text { eccentricity }\end{array}$ \\
\hline \multirow{4}{*}{ G6-G60 ${ }^{b}$} & G6-G60-C & \multirow{4}{*}{$\begin{array}{l}\text { GFRP } \\
6 \# 4\end{array}$} & \multirow{4}{*}{$\begin{array}{c}\text { GFRP } \\
\text { \#3@60 mm }\end{array}$} & \multirow{4}{*}{ - } & Concentric \\
\hline & G6-G60-E25 & & & & $25 \mathrm{~mm}$ \\
\hline & G6-G60-E50 & & & & $50 \mathrm{~mm}$ \\
\hline & G6-G60-F & & & & Flexural \\
\hline \multirow{4}{*}{ G6-G30 ${ }^{\mathrm{b}}$} & G6-G30-C & \multirow{4}{*}{$\begin{array}{l}\text { GFRP } \\
6 \# 4\end{array}$} & \multirow{4}{*}{$\begin{array}{c}\text { GFRP } \\
\text { \#3@30 mm }\end{array}$} & \multirow{4}{*}{-} & Concentric \\
\hline & G6-G30-E25 & & & & $25 \mathrm{~mm}$ \\
\hline & G6-G30-E50 & & & & $50 \mathrm{~mm}$ \\
\hline & G6-G30-F & & & & Flexural \\
\hline \multirow{4}{*}{ CG6-G60 } & CG6-G60-C & \multirow{4}{*}{$\begin{array}{l}\text { GFRP } \\
6 \# 4\end{array}$} & \multirow{4}{*}{$\begin{array}{c}\text { GFRP } \\
\text { \#3@60 mm }\end{array}$} & \multirow{4}{*}{$\begin{array}{l}\text { Two layers } \\
\text { CFRP sheet }\end{array}$} & Concentric \\
\hline & CG6-G60-E25 & & & & $25 \mathrm{~mm}$ \\
\hline & CG6-G60-E50 & & & & $50 \mathrm{~mm}$ \\
\hline & CG6-G60-F & & & & Flexural \\
\hline
\end{tabular}

${ }^{\mathrm{a}}$ All specimens are $205 \mathrm{~mm}$ in diameter and $800 \mathrm{~mm}$ in height

${ }^{\mathrm{b}}$ Adopted from Hadi et al. (2016)

644

645

646

647

648

649

650

651 
Table 2. Experimental results of tested column specimens under concentric load

\begin{tabular}{|l|c|c|c|}
\hline \multicolumn{1}{|c|}{ Specimen } & G6-G60-C & G6-G30-C & CG6-G60-C \\
\hline First peak load $(\mathrm{kN})$ & 1220 & 1309 & - \\
\hline Second Peak load $(\mathrm{kN})$ & 1425 & 2041 & 3068 \\
\hline Load of GFRP bars at second peak load $\left(\mathrm{P}_{\mathrm{bar}}\right)^{\mathrm{a}}$ & 307 & 494 & 593 \\
$(\mathrm{kN})$ & & & 75.8 \\
\hline Experimental confined concrete strength ${ }^{\mathrm{b}}(\mathrm{MPa})$ & 55.6 & 76.9 & 76.1 \\
\hline Calculated confined concrete strength $^{\mathrm{c}}(\mathrm{MPa})$ & 55.5 & 75.8 & \\
\hline
\end{tabular}

${ }^{\mathrm{a}} P_{b a r}=\varepsilon_{b a r} E_{f} A_{b a r}$

${ }^{\mathrm{b}}$ Calculated using Eq. (25)

${ }^{\mathrm{c}}$ Calculated using Eq. (8) 
Table 3. Experimental results of tested column specimens under eccentric loads

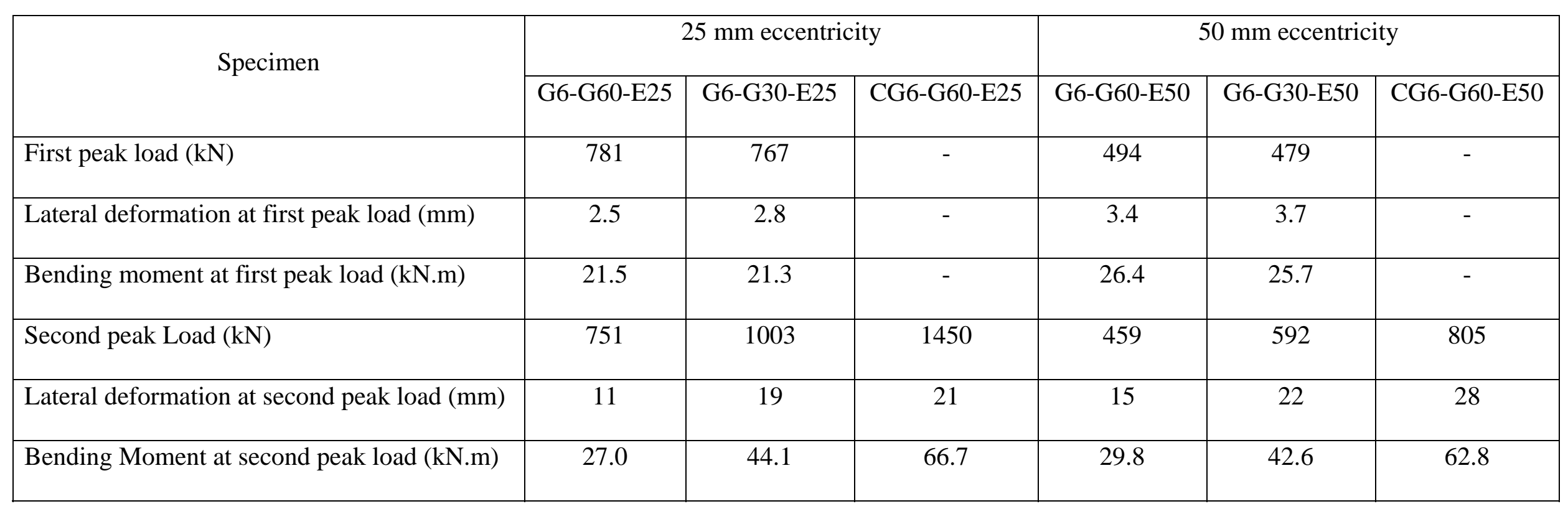


Table 4. Experimental results of tested beam specimens under flexural load

\begin{tabular}{|l|c|c|c|}
\hline Specimen & G6-G60-F & G6-G30-F & CG6-G60-F \\
\hline First peak load (kN) & 247 & 242 & - \\
\hline Bending moment at first peak load (kN.m) & 28.8 & 28.2 & - \\
\hline Second peak Load (kN) & 268 & 452 & 478 \\
\hline Bending moment at second peak load (kN.m) & 31.3 & 29.9 & 55.8 \\
\hline
\end{tabular}




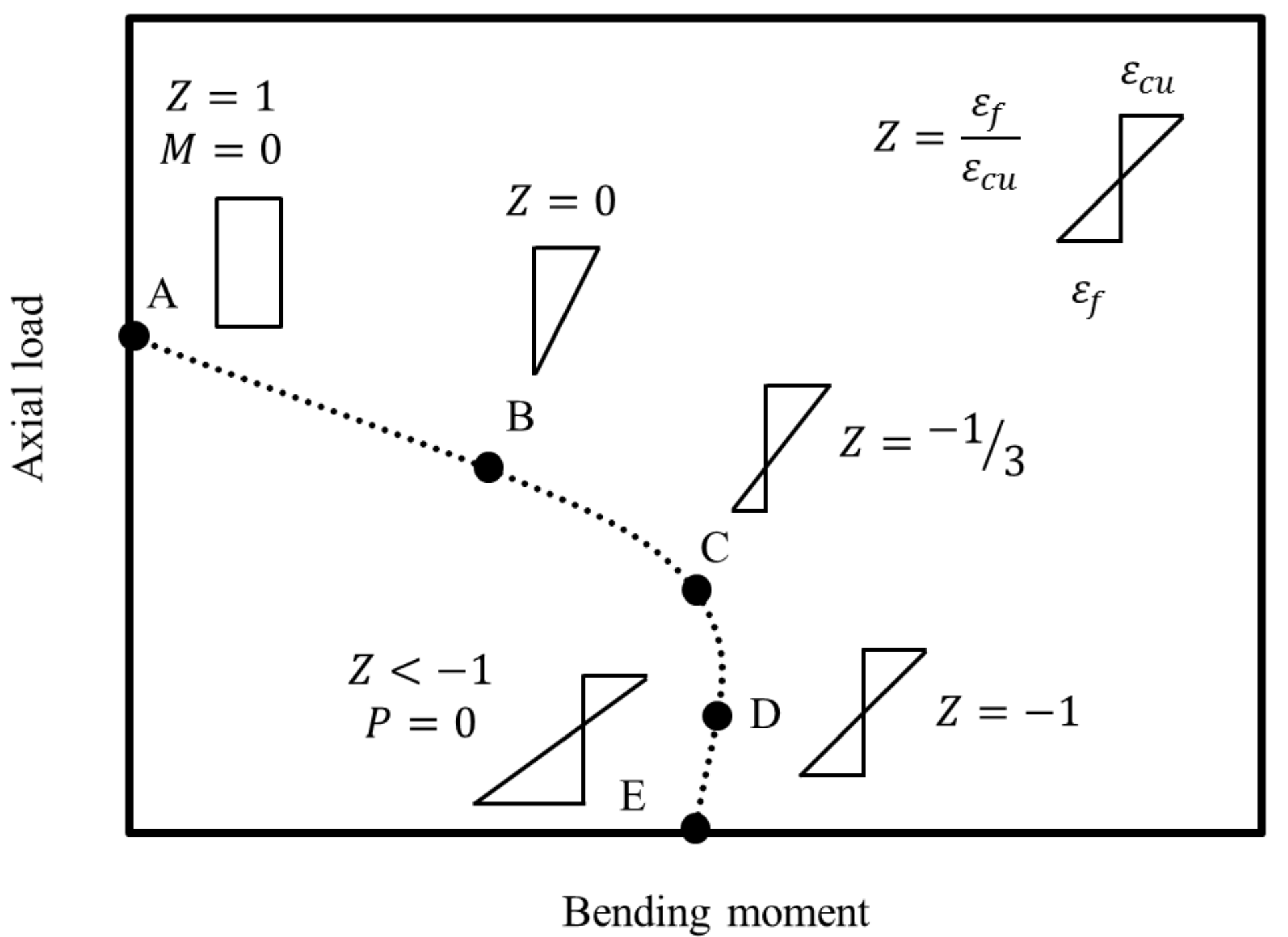

Fig. 1. Schematic drawing of analytical peak $P_{n}-M_{n}$ diagram based on five points 


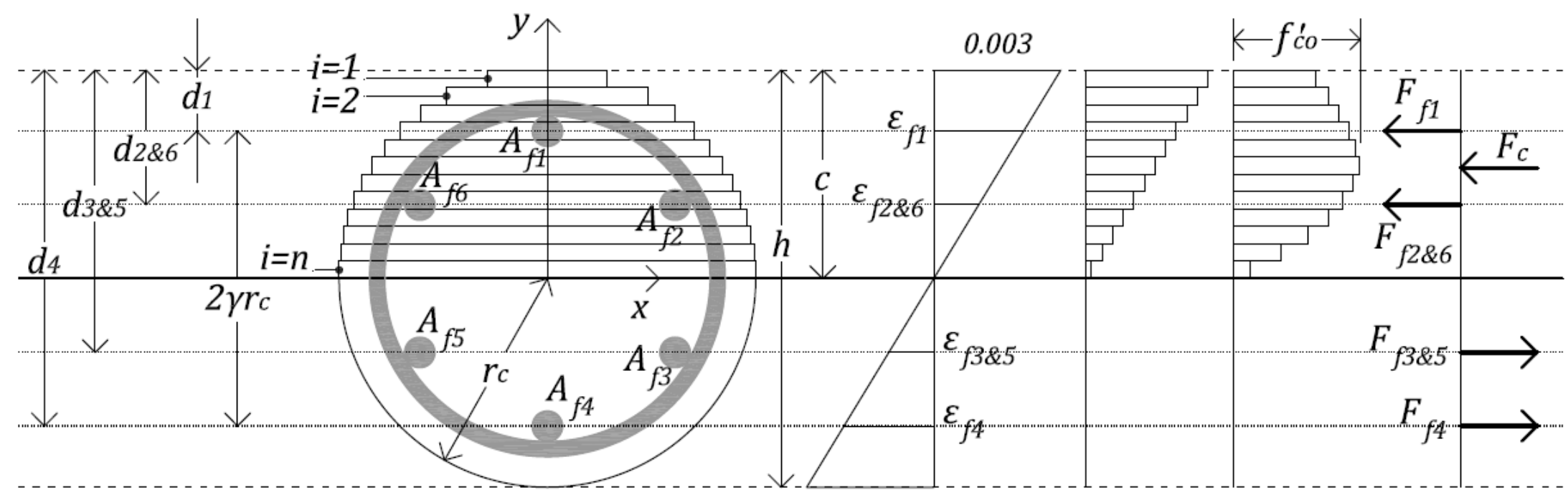

(a)

Cross-section

Strain

Equivalent strain Equivalent stress Resultant distribution in concrete strips in concrete strips forces

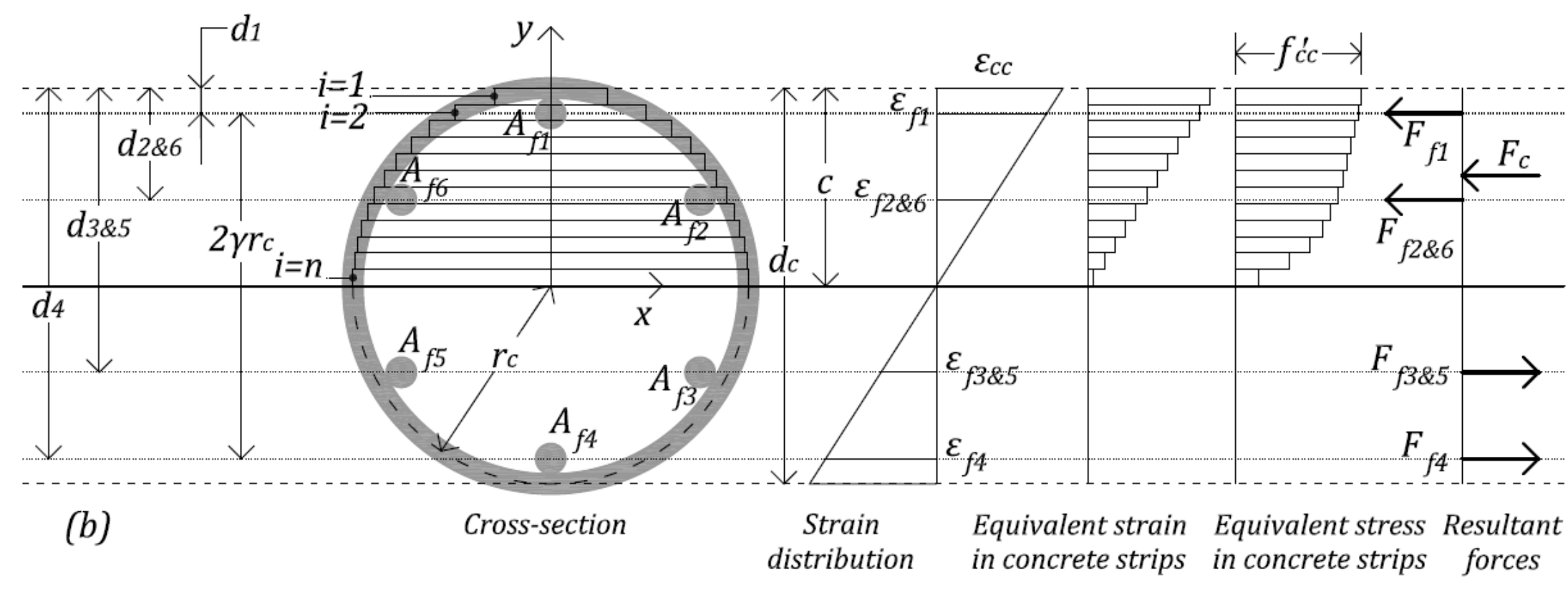

Fig. 2. Analysis of GFRP-RC cross-section: (a) first peak load; and (b) second peak load 


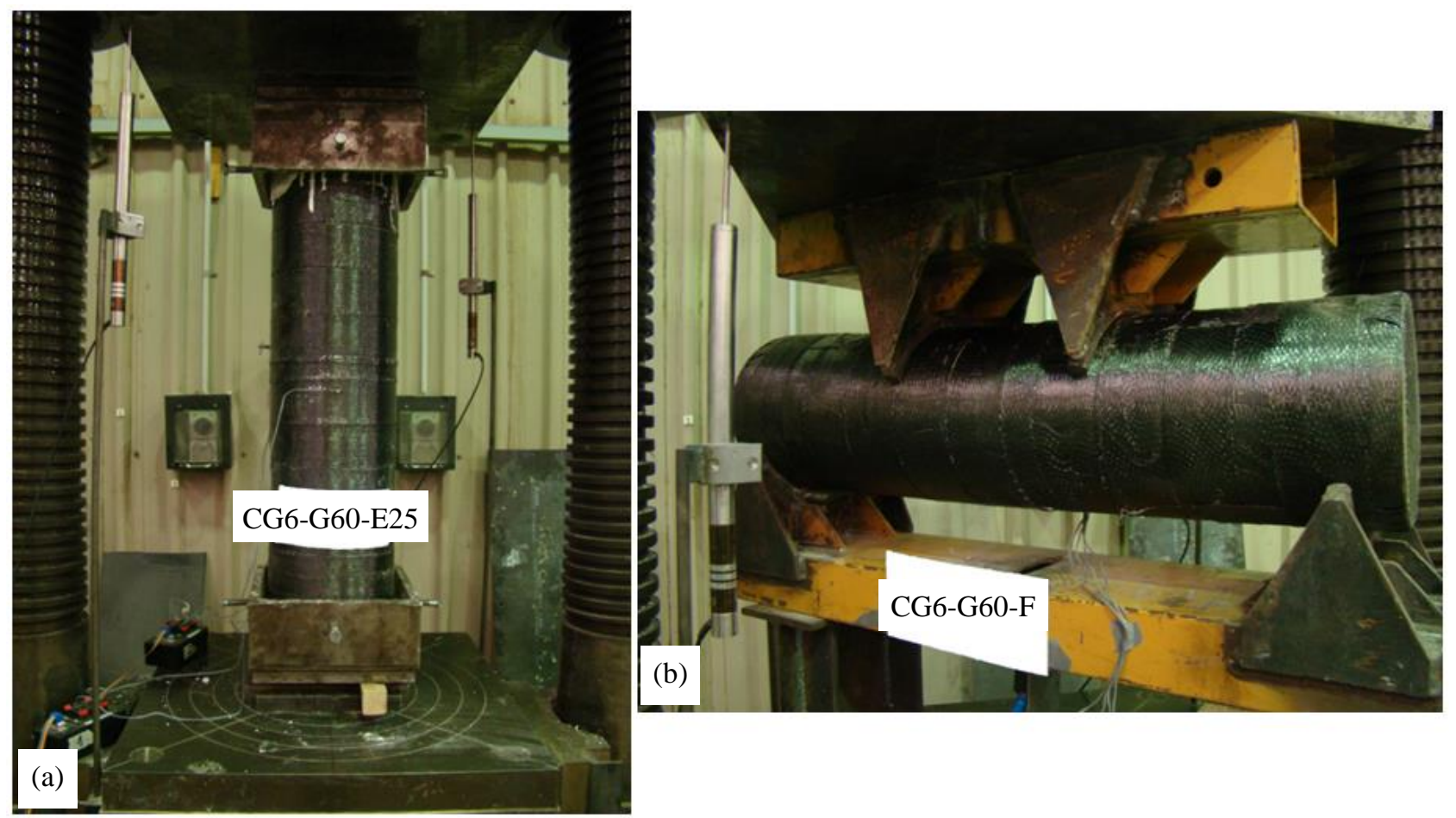

Fig. 3. Typical test setup; (a) CG6-G60-E25; and (b) CG6-G60-F 


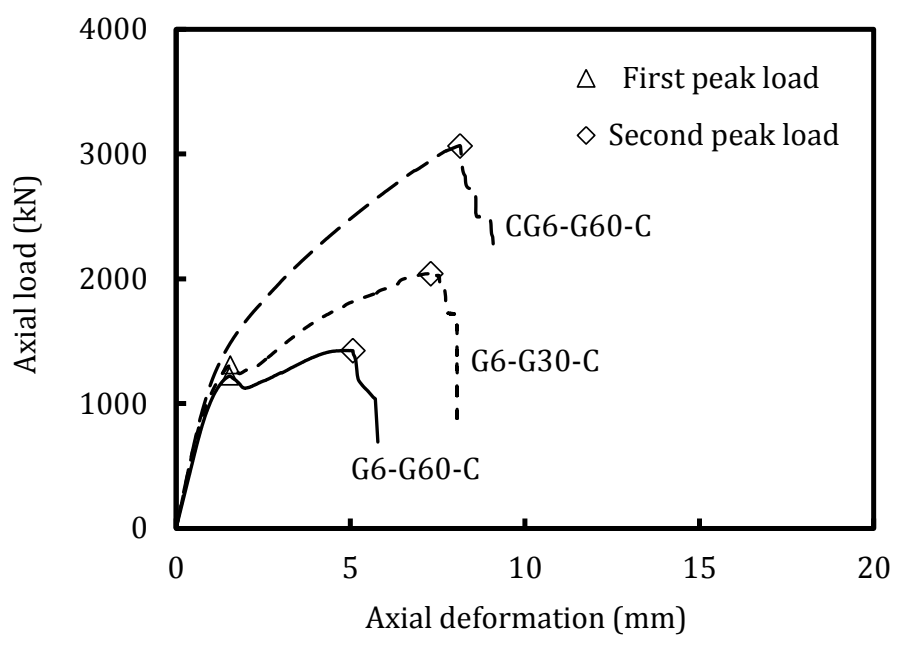

Fig. 4. Axial load-axial deformation behavior of column specimens tested under concentric load 

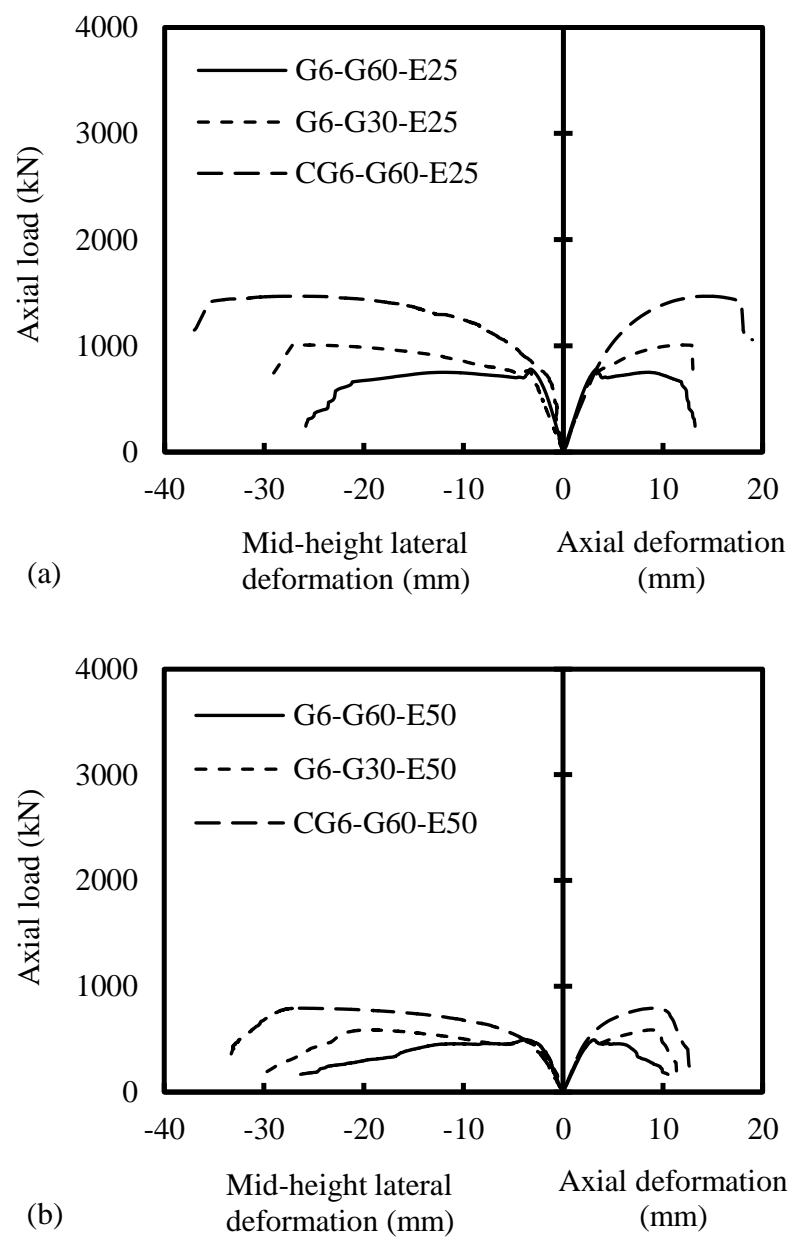

Fig. 5. Axial load-deformation behavior of column specimens tested under eccentric loads:

(a) $25 \mathrm{~mm}$ eccentricity; and (b) $50 \mathrm{~mm}$ eccentricity 


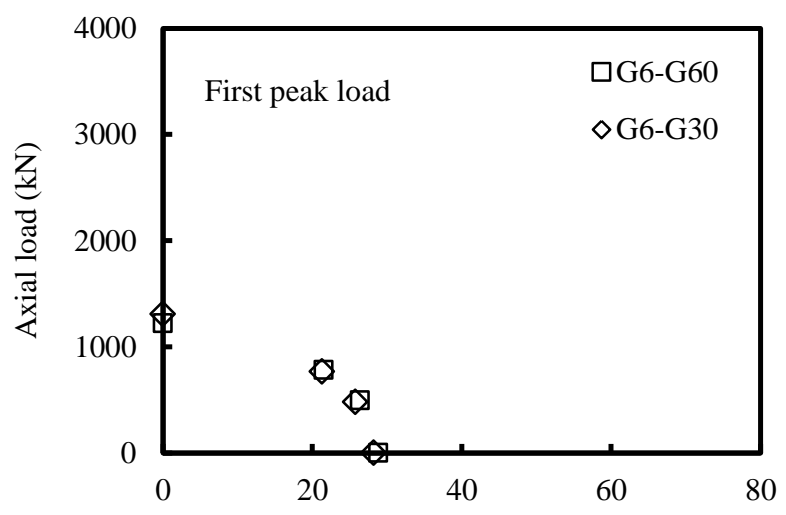

(a) Bending moment (kN.m)

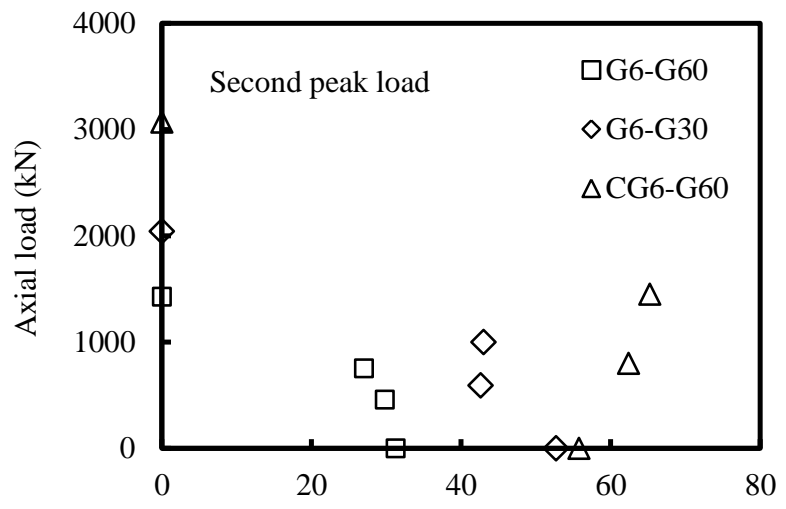

(b)

Bending moment (kN.m)

Fig. 6. Experimental peak $P_{n}-M_{n}$ diagrams of the tested specimens:

(a) first peak load; and (b) second peak load 

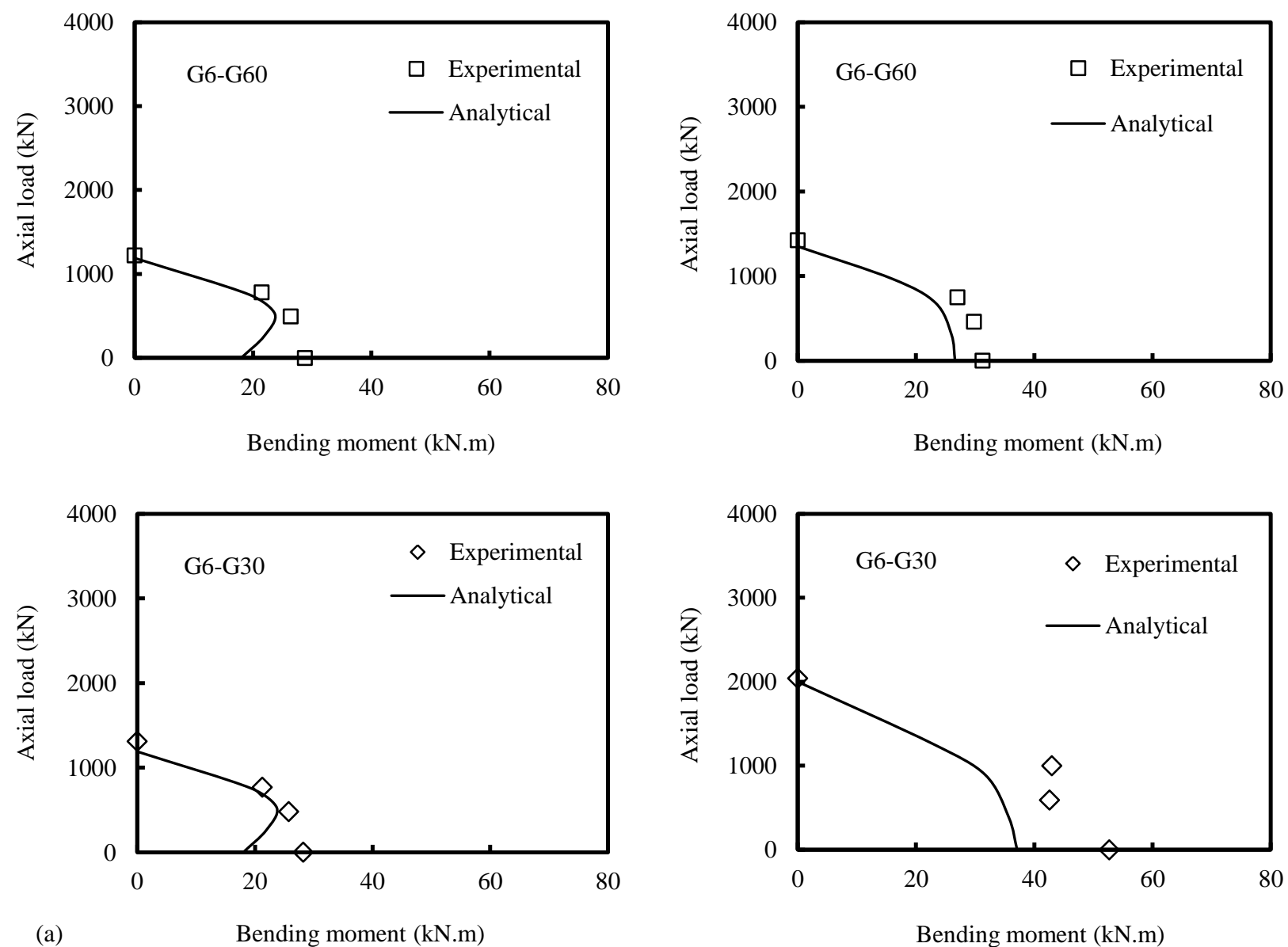

(a) Bending moment (kN.m)

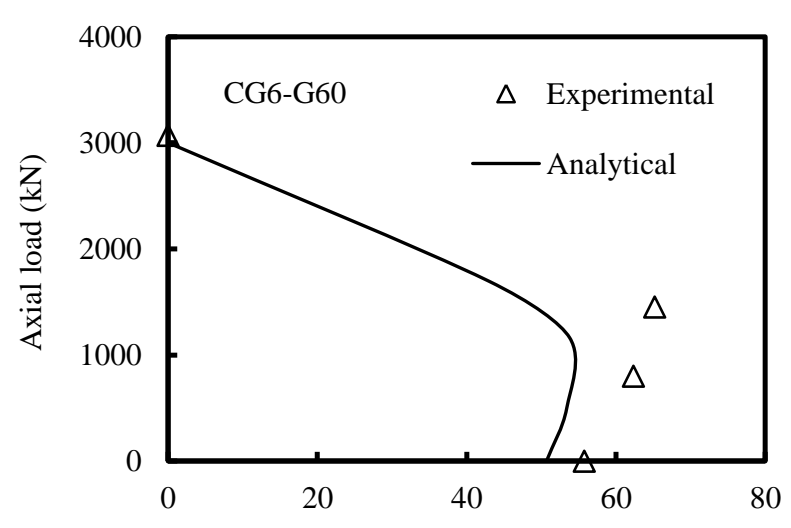

(b) Bending Moment (kN.m)

Fig. 7. Experimental and calculated peak $P_{n}-M_{n}$ diagrams: (a) based on the first peak load of the axial load-axial deformation behavior; and (b) based on the second peak load of the axial load-axial deformation behavior 

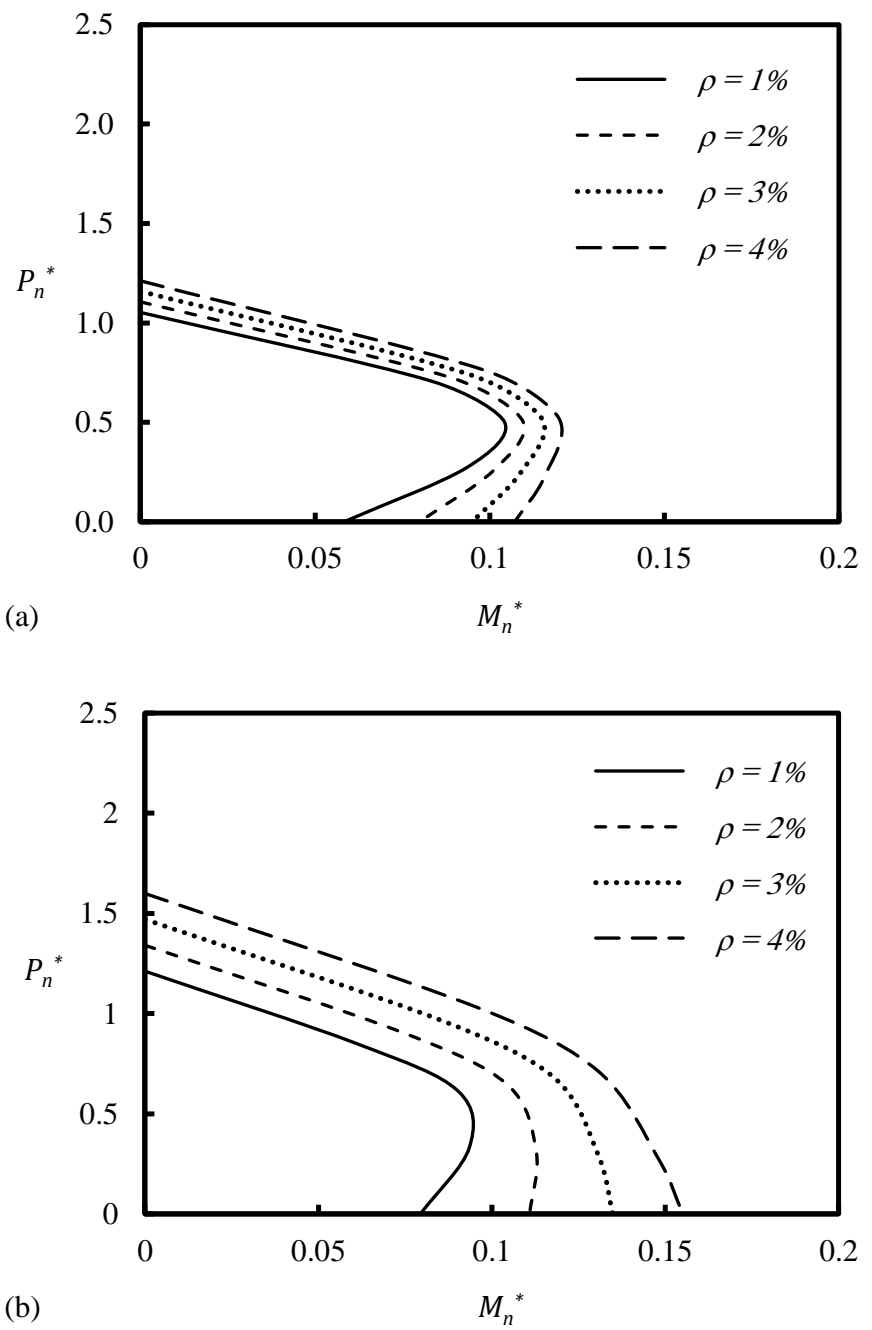

Fig. 8. Effect of $\rho_{f}$ on the peak $P^{*}-M^{*}$ diagrams: (a) first peak $P^{*}-M^{*}$ diagram; and (b) second peak $P^{*}-M^{*}$ diagram 


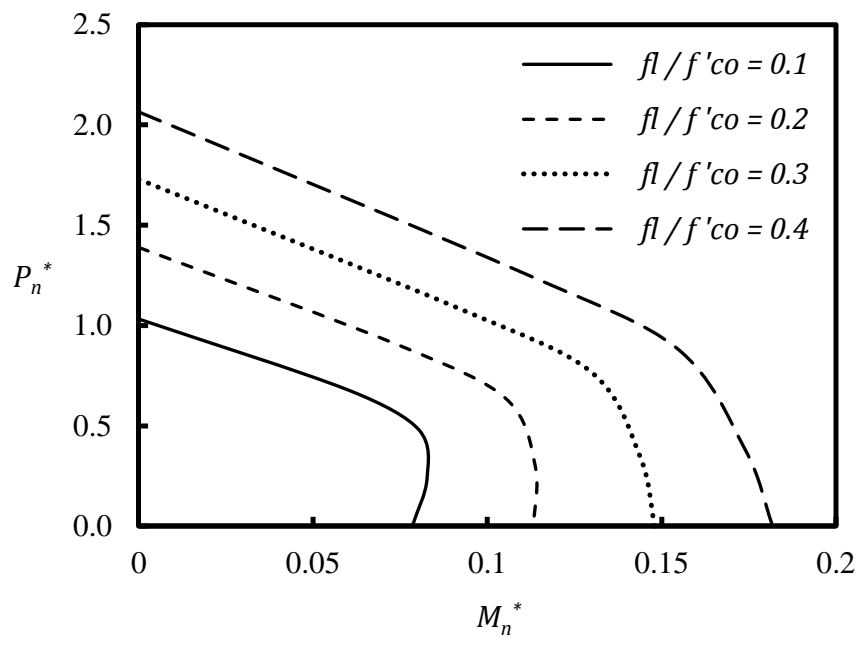

Fig. 9. Effect of $f_{l} / f_{c o}^{\prime}$ on second peak $P^{*}-M^{*}$ diagram 


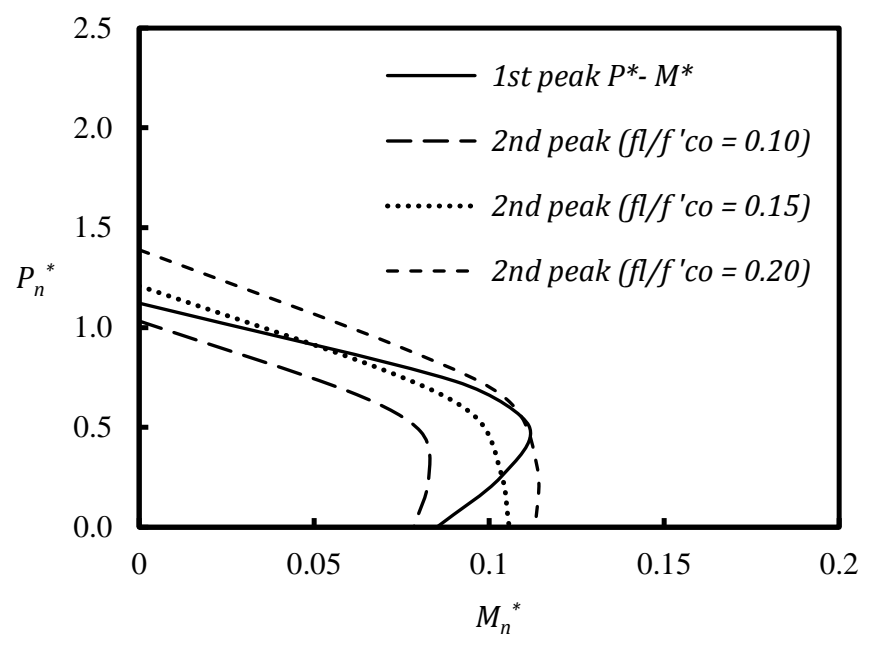

Fig. 10. Comparison between first and second peak $P^{*}-M^{*}$ diagrams for different $f_{l} / f_{c o}^{\prime}$ 


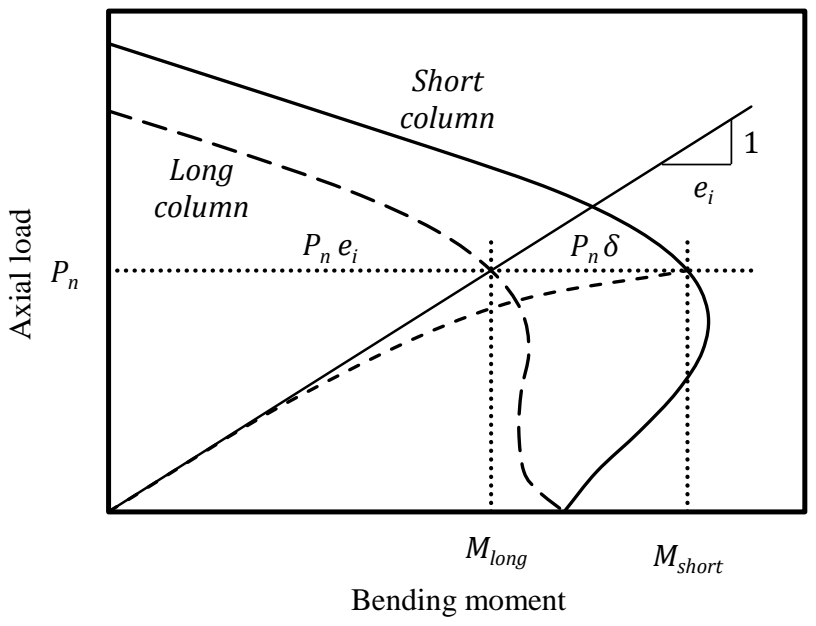

Fig. 11. Typical peak $P^{*}-M^{*}$ diagram for short and long FRP-RC columns 


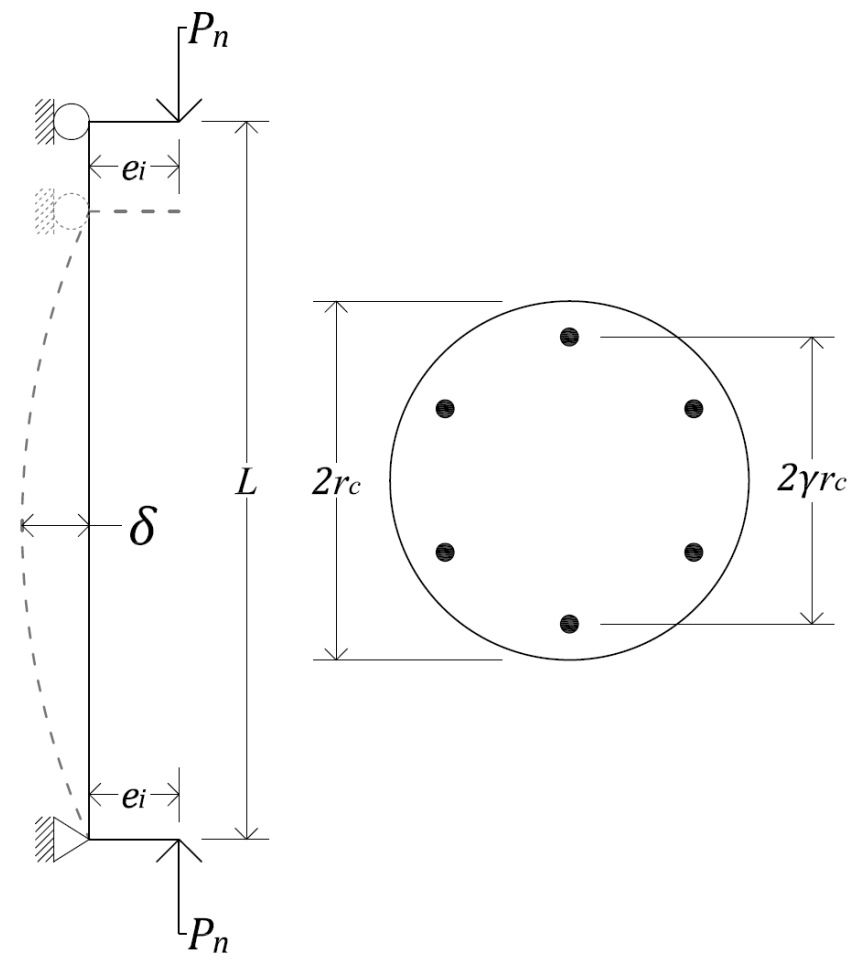

Fig. 12. Typical deformation of pin-ended single curvature column 

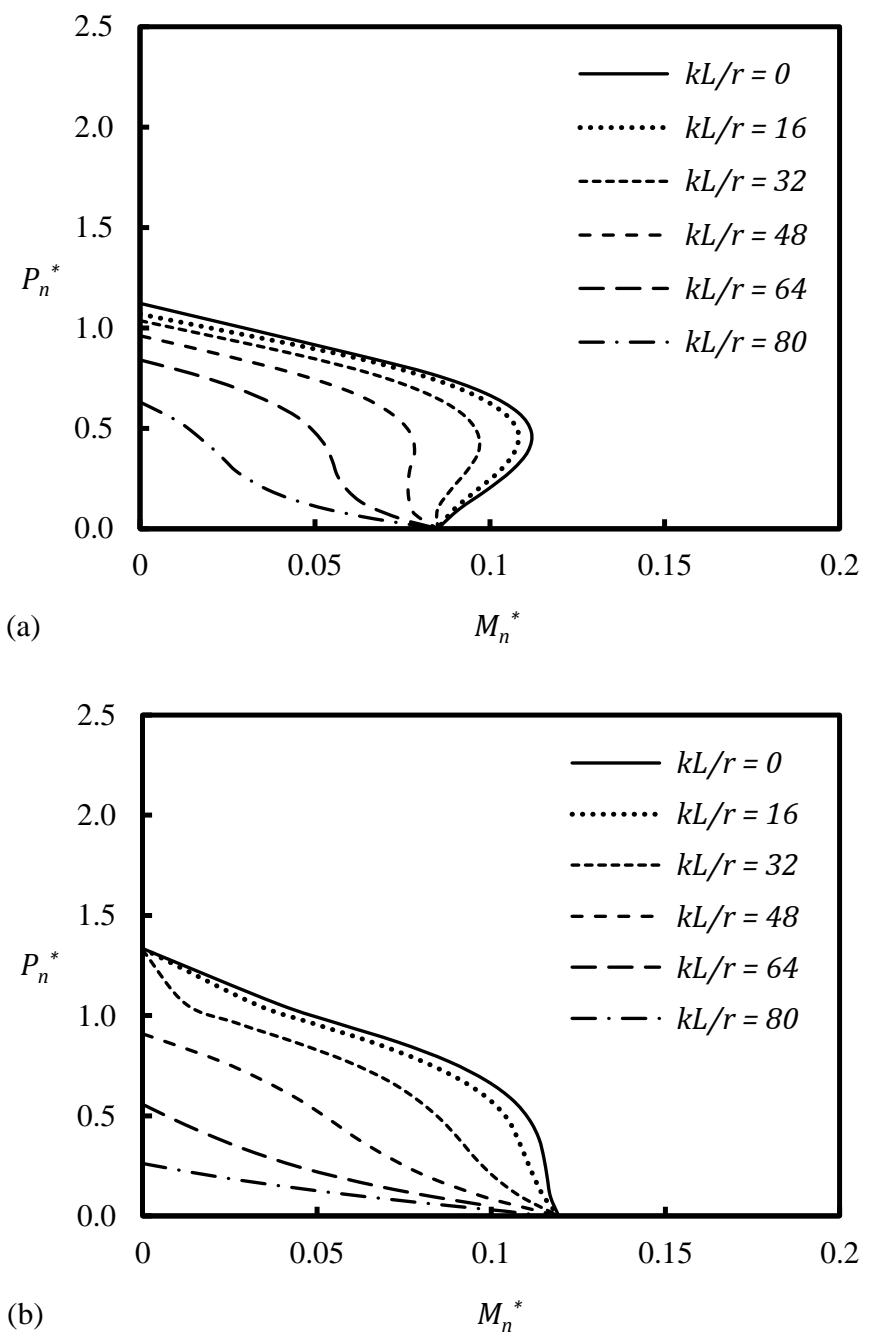

Fig. 13. Effect of $k L / r$ on the peak $P^{*}-M^{*}$ diagrams: (a) first peak $P^{*}-M^{*}$ diagram; and (b) second peak $P^{*}-M^{*}$ diagram 


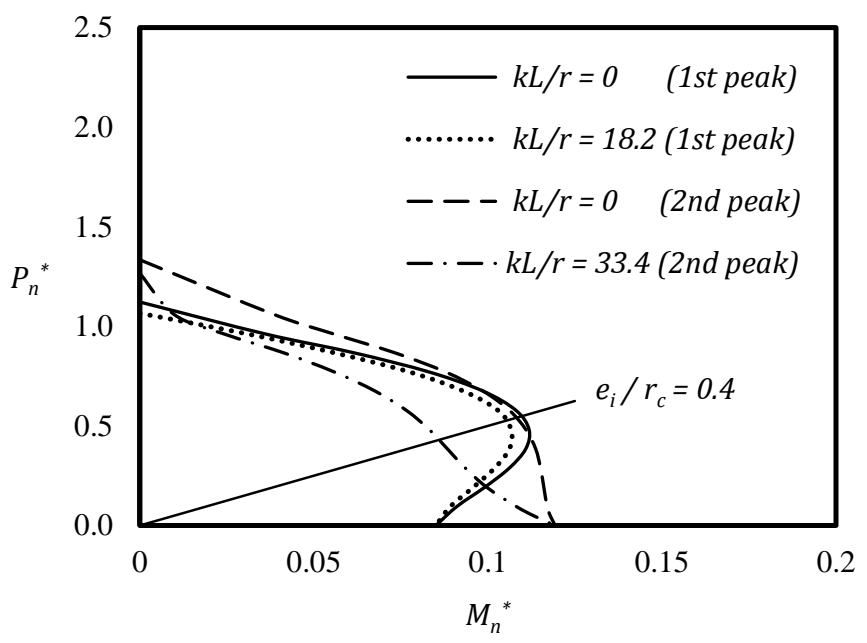

Fig. 14. First and second peak $P^{*}-M^{*}$ diagrams for short and long columns with $5 \%$ strength reduction under concentric load 